\title{
Mechanical Properties of Concrete After Chlorine Salt Extraction in Freeze-Thaw Environment
}

\author{
Liu Faming ${ }^{*}, 1$, Ye Shujin ${ }^{2}$ and Ma Jie ${ }^{3}$ \\ ${ }^{1}$ School of Resources and Civil Engineering, Suzhou University, Suzhou, Anhui, 234000, P.R. China \\ ${ }^{2}$ Department of Architecture Administration, Huainan, Anhui, 232000, P.R. China \\ ${ }^{3}$ School of Resources and Civil Engineering, Suzhou University, Suzhou, Anhui, 234000, P.R. China
}

\begin{abstract}
Steel corrosion caused by chlorine salt erosion, degrade performance of reinforced concrete structures. Lead to can't use or need to reinforce the maintenance structure, produce the huge economic losses. The research of this subject is also a worldwide difficult problem. The freeze-thaw damage of concrete is a complex process of physical change. The chlorine salt erosion is often accompanied by freezing and thawing process. Make concrete structure is in a very bad environment. According to different sources of chloride ion and adopt general international electrochemical chloride extraction testing method of concrete specimens after different freezing and thawing times, the effect of chloride extraction, compressive strength, permeability resistance are studied. It is concluded that the chloride extraction, the strength and durability of the concrete member after freezing and thawing has had certain improvement, especially the durability has a lot to improve. In addition, put forward to increase thickness of concrete cover, preferable high-performance concrete resistance to chloride, strictly control the content of chlorine ion in concrete raw materials, adding reinforcement rust and corrosion inhibitor, adopting concrete corrosion layer, special steel, cathodic protection and so on measures to prevent the chlorine salt erosion. For electrochemical chloride extraction technique in reinforced concrete hydraulic structure, the application of civil engineering in the marine environment which it is provided the theoretical foundation and promotion.
\end{abstract}

Keywords: Chlorine salt erosion, durability electrochemical chloride extraction, freeze-thaw.

\section{INTRODUCTION}

In recent years, our country's infrastructure is continuous high-speed growth. The size of the infrastructure is also growing. The construction of the urban agglomeration, urban belt constantly refresh the construction scale. The emerging urban development zone construction are also refresh the dosage of the reinforced concrete. Currently the world's biggest civil engineering construction it is in China. The case of civil structure instability due to reinforced concrete durability deterioration is so many. Such as in 1989, the United States department of transportation, according to a report of the interstate highway bridges due to the economic consequences of the steel corrosion damage cumulative up to $\$ 150$ billion [1]. Japan annual used for strengthening and repairing the chlorine salt erosion environment civil engineering cost up to $\$ 850000$. A 16 layer reinforced concrete structure in Qingdao is less than $100 \mathrm{~m}$ from the coast, floor reinforcement corroded seriously only use 3 years, lead to structural instability, had to overall demolition [2].

*Address correspondence to this author at the School of Resources and Civil Engineering, Suzhou University, Anhui, 234000, P.R. China;

Tel: 15005578576; E-mail: 94502161@qq.com
There are various factors affecting the durability of concrete structures, and complex between the various factors, connect with each other. In general it is can be divided into two aspects of internal factors and external factors. Internal cause including alkali aggregate reaction, volume shrinkage, water cement ratio, cover thickness, maintenance, quality, etc. The external cause includes friction, erosion, environment temperature, fatigue stress, fracture weathering, load, etc. According to these factors, the various countries' scholars conducted a lot of scientific research. Mainly related to material, structure, environment and artifacts. Among them, the chlorine salt erosion caused by the concrete structure durability degradation is important and difficult issues of common concern to civil engineering. Although electrochemical chloride extraction technology attracted much attention in recent years, but for the mechanical behavior of concrete after freeze-thaw environment in addition to chlorine change research is not deep enough. China's mainland coastline of 18000 kilometers, coupled with freeze-thaw environment. If not in-depth research and discussion, is bound to the civil engineering disasters caused by lack of concrete durability of serious, leading to the country's huge economic burden and pressure. 


\section{CHLORINE SALT CORROSION MECHANISM OF FREEZE-THAW ENVIRONMENT}

Due to factors such as material itself and the construction quality, concrete material within different types and size of pore and connecting hole. The environment of various harmful substances by diffusion, adsorption and permeation, electrochemical action into the concrete internal structure. Harmful substances contact with reinforcement corrosion. Source of chlorine ion in concrete are mainly two kinds. One kind is add chlorine salt production in concrete mixing process. Such as using an seawater and sea sand mixing concrete, with chloride in the cement, aggregate and water, mixed with admixture containing chloride, etc. Another kind is by the external environment of chloride erosion to inside the concrete. Such as sea water environment, the salt lake region, ice salt concrete structure in the environment, spilling chloride brine in order to remove snow, etc.

In the hydration process of cement produce, $\mathrm{NaOH}$, $\mathrm{Ca}(\mathrm{OH})_{2}, \mathrm{Al}(\mathrm{OH})_{3}$ and $\mathrm{KOH}$. Make the concrete inside alkali environment. The alkali can produce density of passivation membrane on steel surface, to protect steel in the normal environment from erosion. However, chlorine ion can be preferred in the steel surface adsorption, reinforced passive film surface chloride ion concentration is much higher than the chloride ion concentration in pore solution. The high alkalinity environment lower rapidly, local can form acid environment, lead to passive film disappear. In addition, chloride ion can breakdown passive film which are weak, react with metallic iron ion. Exposed metal became a corrosion cell anode, large area not breakdowned of passivation film as cathode. The cathode and anode corrosion cell formed a small pit corrosion phenomenon, both on the steel surface passivation membrane damage after will form a larger potential difference, began to produce electrochemical corrosion, steel corrosion [3].

In the freeze-thaw environment, the concrete pore is in a state of supercooled water molecules. Because its vapor pressure is higher than the vapor pressure of ice with temperatures and pressure to the wool stoma in the interface of ice penetration. Produce a kind of osmotic pressure. The permeability result is bound to make the wool stoma of ice volume further expansion.

So the saturated state of the concrete in cold, the capillary wall under inflation pressure and seepage pressure at the same time. When the two pressure produced in the concrete tensile stress exceeds the tensile strength. The concrete is cracking [4]. Accordingly, chlorine salt and concrete structure under the action of freeze-thaw environment destruction are more serious and thorough. Should it is cause an important problem in civil engineering design and construction to consider.

\section{GENERAL SITUATION OF TEST}

\subsection{Raw Materials}

This experiment cement were used $42.5 \mathrm{R}$ ordinary portland cement, technical performance meet the requirements of the relevant national standards. Coarse aggregate were used maximum particle size gradation of $20 \mathrm{~mm}$ good gravel, silt content less than $0.5 \%$. Fine aggregate for ordinary river sand, the maximum particle size of $5 \mathrm{~mm}$, continuous gradation, fineness modulus of 2.96, the silt content $1.9 \%$. Class I fly ash. For the study of concrete specimens before and after the chloride extraction compressive strength, flexural strength, resistance to the permeability resistance changes and simulation chlorine salt environment. When the specimen shape, $3 \%$ of the total quality of sodium chloride salt mixed with cement and fly ash. The mix proportion of concrete are shown in Table $\mathbf{1}$.

\subsection{Specimen of Production}

According to the natural freeze-thaw cycle test performance and durability of concrete long-term test method (GBJ82-85) and different test purpose, produced different specifications of the specimen. Adopt the method of electrochemical chloride extraction experiment. Cathode galvanized iron is buried in the middle of the specimen area, after concrete specimen molding with wire leads. Connect the dc regulated power supply. Needed for the test specimen are shown in Table 2.

All specimens in standard curing box cured 28 days, then remove the freezing and thawing of the specimen in the water for 2 days. Wipe water on the surface of the specimen with a dry towel, and then put these specimens into the TDR-16 freeze-thaw machine. The effect of chlorine extraction testing of freeze-thaw cycles were calculated at 25, 50 and 75 times. Freeze-thaw cycles of concrete compressive strength and permeability resistance were

Table 1. Concrete mixture ratio. (1-1).

\begin{tabular}{|c|c|c|c|c|}
\hline \multicolumn{5}{|c|}{ Per cubic meter of concrete material consumption (kg) } \\
\hline Water & Cement & Sand & Gravel & Fly ash \\
\hline \hline 175 & 300 & 710 & 1105 & 100 \\
\hline
\end{tabular}

(1-2).

\begin{tabular}{|c|c|c|}
\hline Water -cement ratio & Sand ratio (\%) & Ratio (water:cement:sand:gravel) \\
\hline \hline 0.44 & 39.1 & $0.44: 1: 1.77: 2.76$ \\
\hline
\end{tabular}


calculated at 75 times.

\subsection{Test Program}

Chlorine extraction are based on current density and electricity of these two important technical parameter. The compressive strength and permeability respective in freeze-thaw times and current density change parameters, electricity is always $2000 \mathrm{~A} \cdot \mathrm{h} \cdot \mathrm{m}^{-2}$, the times of freeze-thaw, current density and electricity of the experiment are shown in
Table 3. It is produced 10 specimens in accordance with this test. The determination of chloride ion content in testing code of concrete for port and waterwog engineering (JTJ270-1998). The compressive strength test in accordance with Standard for test method of mechanical properties on ordinary concrete (GBJ-85). The permeability test of penetration depth method is used to measure relative permeability coefficient.

Table 2. Test specimen table (2-1)

\begin{tabular}{|c|c|}
\hline Test project & Specimen size \\
\hline \hline Chloride extraction effect & $100 \mathrm{~mm} \times 100 \mathrm{~mm} \times 300 \mathrm{~mm}$ \\
\hline Compressive strength & $150 \mathrm{~mm} \times 150 \mathrm{~mm} \times 150 \mathrm{~mm}$ \\
\hline permeability resistance & Top diameter $175 \mathrm{~mm}$, follow diameter $185 \mathrm{~mm}$, highly $150 \mathrm{~mm}$ \\
\hline
\end{tabular}

(2-2)

\begin{tabular}{|c|c|}
\hline Specimen number & Cathode materials \\
\hline \hline A & HRB400 12 steel \\
\hline B & iron \\
\hline C & iron \\
\hline
\end{tabular}

Table 3. Test change parameter table. (3-1).

\begin{tabular}{|c|c|}
\hline Test project & Times of freeze-thaw \\
\hline \hline Chloride extraction effect & $0 、 50,75$ \\
\hline Compressive strength & $0,50 、 75$ \\
\hline permeability resistance & $0,50,75$ \\
\hline
\end{tabular}

(3-2).

\begin{tabular}{|c|c|}
\hline Electricity $\left(\mathbf{2 0 0 0 A} \cdot \mathbf{h} \cdot \mathbf{m}^{-\mathbf{2}}\right)$ & Current Density $\left(\mathbf{A} \cdot \mathbf{m}^{-2}\right)$ \\
\hline \hline 2000 & $0 、 1.0 、 2.0 、 3.0$ \\
\hline 2000 & $0,1.0 、 2.0 、 3.0$ \\
\hline 2000 & $0 、 1.0 、 2.0 、 3.0$ \\
\hline
\end{tabular}

\section{THE RESULTS AND ANALYSIS OF TEST}

\subsection{The Results of Test}

Table 4. The results of concrete specimens performance test table (4-1).

\begin{tabular}{|c|c|c|}
\hline Times of Freeze-thaw & Electricity $\left(2000 \mathrm{~A} \cdot \mathbf{h} \cdot \mathrm{m}^{-2}\right)$ & Current Density $\left(A \cdot \mathbf{m}^{-2}\right)$ \\
\hline \multirow{2}{*}{0} & \multirow[t]{2}{*}{2000} & 2.0 \\
\hline & & 3.0 \\
\hline
\end{tabular}


Table (4-1). Contd.....

\begin{tabular}{|c|c|c|}
\hline Times of Freeze-thaw & Electricity $\left(2000 A \cdot h \cdot m^{-2}\right)$ & Current Density $\left(\mathbf{A} \cdot \mathbf{m}^{-2}\right)$ \\
\hline \multirow{3}{*}{50} & \multirow{3}{*}{2000} & 1.0 \\
\hline & & 2.0 \\
\hline & & 3.0 \\
\hline \multirow{3}{*}{75} & \multirow{3}{*}{2000} & 1.0 \\
\hline & & 2.0 \\
\hline & & 3.0 \\
\hline
\end{tabular}

(4-2)

\begin{tabular}{|c|c|c|c|}
\hline Specimen Number & Begin of the Chloride Ion Content \% & Last of the Chloride Ion Content \% & Chloride Extraction Effect \% \\
\hline A2 & \multirow{2}{*}{0.582} & 0.272 & 53.3 \\
\hline A3 & & 0.261 & 55.2 \\
\hline B1 & \multirow{3}{*}{0.576} & 0.286 & 50.3 \\
\hline $\mathrm{B} 2$ & & 0.251 & 56.4 \\
\hline B3 & & 0.239 & 58.5 \\
\hline $\mathrm{C} 0$ & \multirow{2}{*}{0.563} & 0.563 & 0 \\
\hline $\mathrm{C} 3$ & & 0.191 & 66.1 \\
\hline
\end{tabular}

(4-3)

\begin{tabular}{|c|c|}
\hline The Compressive Strength After Chloride Extraction (Mpa) & Relative Permeability After Chloride Extraction $\left(\mathbf{1 0}^{-\mathbf{3}} \mathbf{m m} \cdot \mathbf{h}^{-\mathbf{1}}\right)$ \\
\hline \hline 31.62 & 14.27 \\
\hline 31.69 & 13.36 \\
\hline 32.72 & 6.72 \\
\hline 32.94 & 5.24 \\
\hline 30.87 & 19.48 \\
\hline 29.74 & 18.24 \\
\hline 30.92 & 10.16 \\
\hline 30.18 & 9.42 \\
\hline 26.38 & 30.25 \\
\hline 27.42 & 28.84 \\
\hline
\end{tabular}


Table (4-3). Contd.....

\begin{tabular}{|c|c|}
\hline The Compressive Strength After Chloride Extraction (Mpa) & Relative Permeability After ${\text { Chloride Extraction }\left(\mathbf{1 0}^{-3} \mathbf{m m}^{\circ} \mathbf{h}^{-\mathbf{1}}\right)}^{19.43}$ \\
\hline \hline 26.41 & 18.21 \\
\hline 27.22 & \\
\hline
\end{tabular}

Note: The chloride ion content use the quality of cement and fly ash percentage said. Reinforced concrete specimen surface chloride ion content is from the average depth of chloride ion content.

\subsection{The Analysis of Test Results}

\subsubsection{Chloride Extraction Effect}

In the process of test, it is in different current density of electrochemical chloride extraction. Amount of chloride ions contained in all specimens of the same change trend with the depth. The middle area of chloride ions content is higher than the external and internal. It is mean that close to the cathode steel chlorine ion concentration is higher than other parts of the region. Close to the electrode the chloride effect is better. From Table $\mathbf{4}$ and Fig. (1) can be seen, no matter how much the freeze-thaw cycles, with the increase of current density, the final content of chloride ion is on the declining, the chloride extraction effect increased.

By the different freeze-thaw cycle times, when the current density is $1.0 \mathrm{~A} \bullet \mathrm{m}^{-2}$, the chlorine extraction effect was increased by $45.0 \%, 45.0 \%$ and $45.0 \%$ than no current flow respectively. When the times of freeze-thaw is 0 times, current density increased from $1.0 \mathrm{~A} \cdot \mathrm{m}^{-2}$ to $2.0 \mathrm{~A} \cdot \mathrm{m}^{-2}, 3.0$ $\mathrm{A} \cdot \mathrm{m}^{-2}$, chlorine extraction effect was increased by $18.4 \%$ and $18.4 \%$ respectively. This show that the influence on the effect of current intensity is not obvious. But not with the flow of electricity chlorine extraction effect of the specimens was obvious. This is because the increase of current intensity, can quicken the speed of chloride ion, but little impact on the total number of mobile ions change.

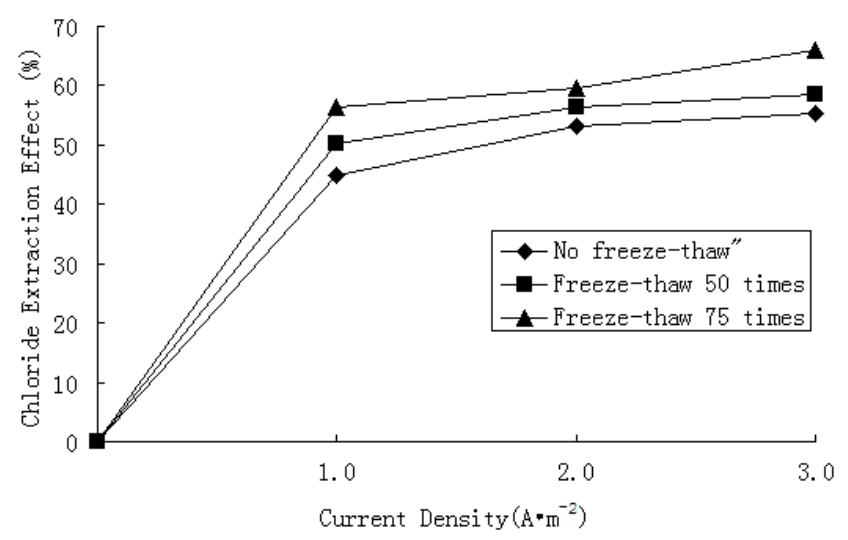

Fig.(1), Chloride extraction effect under different freeze-thaw times and current density.

From Fig. (1), freeze-thaw specimens's curve of chlorine extraction effect are above no freeze-thaw curve. In the same chlorine extraction parameters conditions, freeze-thaw specimen is better than not freeze-thaw. The same condition, freeze-thaw 50 times, 75 times specimens's chloride ion content in finally than chlorine ions eventually without freeze-thaw were decreased by $1.03 \%, 1.03 \%$. When the current density was $3.0 \mathrm{~A} \bullet \mathrm{m}^{-2}$, chlorine extraction effect was increased by $5.98 \%$ and $5.98 \%$ respectively. From the above data under the same electricity, the effect of current density, freeze-thaw specimens and not freeze-thaw specimen little change on the chloride extraction effect. Especially for has little impact on the quantity of the chloride. In addition, the change of current density increased chlorine extraction effect. It is once again proved that the current density is an important parameter in the process of electrochemical chlorine extraction.

\subsubsection{The Influence of Concrete Compressive Strength after Chlorine Extraction and Freeze-Thaw}

From the test process, after the freeze-thaw cycle of 50 times, 75 times, concrete specimens damage more and more serious. The cement slurry of specimens surface was Peeled off, part of the internal aggregate exposure, longitudinally small concrete surface cracking, quality has a certain loss. Also from Fig. (2), the compressive strength value curves of not freeze-thaw and freeze-thaw specimens is a slowly increase of approximate horizontal line. Strength value almost no change. The curve of the high times of freeze-thaw is in below. After electrochemical chloride extraction of concrete compressive strength is no significant influence, the amount of chloride ion little influence on strength. In addition, unpowered flow density and the freeze-thaw cycle after 50 times, 75 times, compressive strength of concrete specimen loss values are $2.37 \%$ and $2.37 \%$ respectively. When the current density is $3.0 \mathrm{~A} \cdot \mathrm{m}^{-2}$, compressive strength of concrete specimens value loss is $8.38 \%$ and $17.36 \%$ respectively. This shows that with the increase of freeze-thaw times, strength of concrete is falling. Under electricity and not freeze-thaw conditions, the concrete compressive strength is not only no loss, but also increased by $0.22 \%, 3.48 \%$ and $4.17 \%$ respectively. Illustrate the chloride extraction can make the concrete strength increased slightly, but less increase. After freeze-thaw of the specimens after electrochemical chloride extraction can make the concrete strength remain unchanged. Due to the test specimen mixed with fly ash, can make concrete frost resistance increased. So the strength of concrete after freeze-thaw can close to not freeze-thaw specimens strength. 


\subsubsection{The Influence of Concrete Permeability Resistance after Chlorine Extraction and Freeze-Thaw}

From Fig. (3), the relative permeability coefficient decreases with the increase of current density. Electrochemical chloride extraction can increase the permeability resistance of concrete. This is mainly because in the process of chloride extraction, some cationic (such as $\mathrm{Na}^{+}, \mathrm{Ca}^{2+}, \mathrm{K}^{+}$, etc.) under the action of electric field which is moving towards the cathode of the concrete in the wool stoma effectively blocked. On the other hand, these cationic can react with specimens of $\mathrm{OH}^{-}$to generate alkaline hydrogen and oxygen compounds. Hydrogen and oxygen compounds continue to react with silicate products can also fill the wool stoma in concrete. Therefore, the compactness of concrete increases after chlorine extraction, bibulous rate is also weakened obviously on the surface. The penetration resistance is improved. It is also indirectly improve the durability of concrete after the chloride extraction [5].

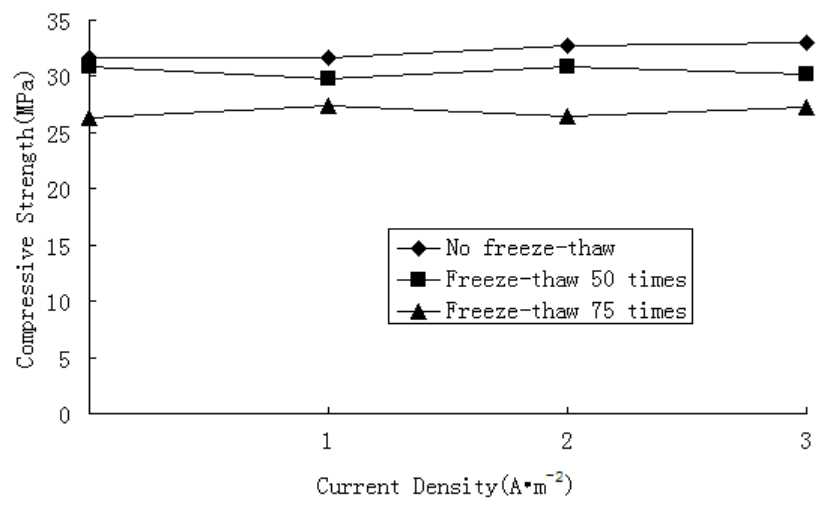

Fig.(2), Compressive strength of concrete specimens under different freeze-thaw times and current density.

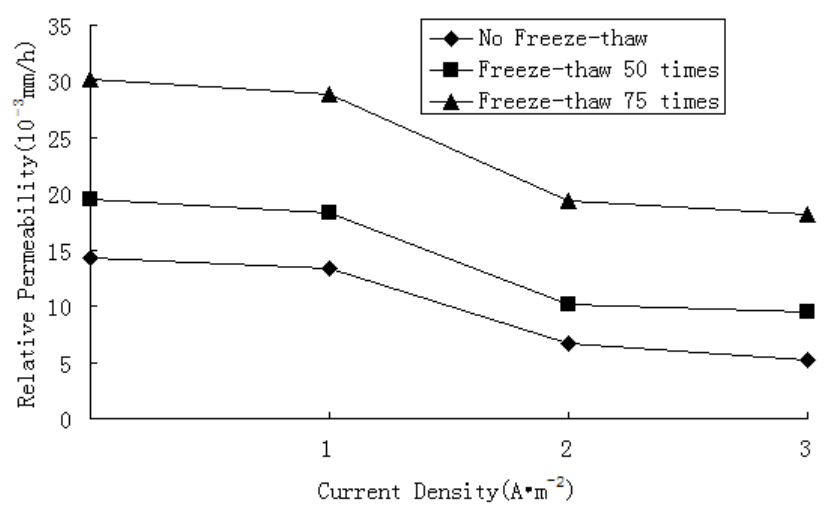

Fig.(3), The relative permeability of concrete specimens under different freeze-thaw times and current density.

Table 4 and Fig. (3) both show that, regardless of how large current density and chloride extraction effect, permeability of concrete after freeze-thaw are significantly increased. The relative permeability is become bigger. The permeability resistance is abate, poor durability. Relative permeability of concrete which no current density and after freeze-thaw 75 times than that of freeze-thaw 50 times increased by $55.29 \%$, increased by $111.98 \%$ than not freeze-thaw. From the data can explain, the concrete under low temperature conditions can cause damage, intensity decreased. Especially has a great influence on the durability of concrete. Freeze-thaw action can cause porosity of hardened concrete's cement slurry increase. Leading to the structure of concrete hydration products by solid state into loose state. With the increase of freeze-thaw cycle times, the contact area in aggregate and cement slurry appear micro fracture and continuous development. In the end because of the separation of aggregates and cement slurry, cause component durability degradation.

\section{CHLORINE SALT CORROSION PREVENTION MEASURES}

In view of the different sources of corrosive chlorine salt, some new steel reinforced concrete structure and especially civil engineering in the marine environment, should be according to the different geographical environment and functional requirements, give priority to prevent measures. Avoid the happening of chlorine salt corrosion and caused by social and economic losses. Through consulting relevant data and the practical engineering experience, put forward the following measures.

(1) Increase the thickness of concrete cover. Chlorine salt corrosion is mainly to steel corrosion. So for prevent the chloride ion contact with steel, can be on the basis of the engineering structure design allows. Increase the path of chloride to steel appropriately. So that the service life of concrete structures are will be extended accordingly. Engineering practice shows that, even the smallest of concrete water-cement ratio and high quality, if in the chlorine salt erosion environment, concrete surface depth of $12 \mathrm{~mm}$ is much higher than the chloride ion content in 25 to $50 \mathrm{~mm}$ depth range [6]. Proposal of concrete member of chlorine salt environment, reinforced protective layer thickness should be not less than $40 \mathrm{~mm}$.

(2) Priority choose high-performance resistance to chloride salt concrete, reduce the chloride ion diffusion coefficient. The strength of concrete is closely related to the density. The higher the density, the durability of concrete is better. With low water-cement ratio, use high-quality configuration mineral admixtures of resistance to chloride salt concrete can effectively reduce the chloride ion diffusion. Increase the compactness of concrete components, effectively prevent the destruction of the chloride ion to reinforced passivation film [7-13].

(3) Strictly control the content of chlorine ion in concrete raw materials and add reinforcement rust and corrosion inhibitor in it. Reduce the amount of chloride ions in concrete raw materials, increase the number of chloride ions from outside. Improve the steel surface chloride ion concentration reaches the critical value of time if in the case of a certain permeability. Rust and corrosion inhibitor can effectively inhibit the admixture of reinforced surface of the cathode reaction. When chloride 
ions put into the concrete, the rust inhibitor and dispersant can happen chemistry with chloride ion. Make the chloride ion lose erosion ability and delay the electrochemical process of reinforcement corrosion [8].

In addition to the above measures, other measures such as adopt the concrete anticorrosive layer, special steel, cathodic protection and relevant technical measures,etc. These measures are the fundamental purpose is to isolate the chloride ion contact with steel. In order to prevent the steel surface passivation film destroyed. Cut off contact between the anode and cathode electrolyte on the surface of the steel [9]. So achieve the purpose of reinforcing steel bar is not eroded.

\section{CONCLUSION}

(1) In this paper, through the performance study of concrete specimens after electrochemical chloride extraction, determine the current density is important parameters of electrochemical chloride extraction. Also further confirmed the electrochemical chloride extraction can effectively remove the chloride ions from concrete.

(2) By different current density of electrochemical chlorine, the chloride ions amount contained in all specimens are the middle area higher than the external and internal. Chlorine ions concentration which close the cathode steel are higher than other parts of the region. It is mean that close to the electrode, the chloride extraction effect is better. Large current density is proposed, which can accelerate electrochemical chloride process, promote the effect of chlorine extraction. In addition, freeze-thaw can also affect the chloride extraction effect, but the impact is not big.

(3) The chloride extraction can make the concrete strength increased slightly. The amount of chloride ions influence on strength is not big. No need to consider in the practical engineering. But the freeze-thaw had a great influence on strength of concrete. Mixing concrete in negative temperature environment should be proper add some additive, such as fly ash, antifreeze, etc. In order to improve the durability of concrete [14].

(4) After electrochemical chloride extraction concrete specimens's surface bibulous rate and overall bibulous rate are lower. The more decrease in the number of pores, the compactness of concrete increases. Obviously it is improved the permeability properties of the concrete structure. But the relative permeability coefficient of concrete after freeze-thaw increases, the permeability resistance reduced, cause component durability degradation. This test measured relative permeability coefficient of concrete's biggest increased by $111.98 \%$.

(5) The chlorine salt erosion caused by steel the effective cross section area decreases, and the formation of stress concentration phenomenon. Under the action of impact load loop or alternating load, will accelerate the destruction of the structures, brittle fracture is likely to occur. In practical engineering, should avoid some harmful ions into the concrete internal structure, brittle fracture is likely to occur. In practical engineering, should avoid some harmful ions into the concrete internal structure, protect steel surface passivation film. At the same time, also avoid a galvanic cell and electrochemical corrosion occurred in the steel surface.

\section{ABOUT THE AUTHORS}

First Author Liu Faming, lecturer of Suzhou University, M.E. The author's major is Durability and Engineering Structure. 3 papers received by EI and 1 patents had been published.

Second Author Ye Shujin, Bachelor degree in engineering, studying for master in Hefei University of Technology. The author's major is Durability and Engineering Structure.

Third Author Ma Jie, lecturer of Suzhou University, M.E. The author's major is Durability and Engineering Structure. 1 papers received by EI had been published.

\section{CONFLICT OF INTEREST}

The authors confirm that this article content has no conflict of interest.

\section{ACKNOWLEDGEMENTS}

This work was financially supported by Suzhou institute of field talented youth fund projects (2013XQRL02). Master research fund start-up project of Suzhou University, Anhui, China (Approval number, 2009YSS04). Construction project in Anhui province (2013YF-19). Anhui province outstanding young talent fund key projects (2013SQRW077ZD). Coal Mine Exploration Engineering Center of Anhui Province (2012YKF14)

\section{REFERENCES}

[1] J. P. Broomfield, Corrosion of Steel in Concrete, London:E\&FN SPON, 1997

[2] P. P. Win, M. Watanabe, A. Machida, "Penetration profile of chloride ion in cracked reinforced concrete", Cement Concrete Res., vol. 34, no. 7, pp. 1056-1070, 2004.

[3] J. A. Gonzalez, S. Feliu, P. Rodriguex, E. Ramírez, C. Alonso, C. Andrade, "Some question on the corrosion of steel in concrete Part 1: when, how and hou much steel corrode", Mat. Struct., vol. 29, pp. 40-46, 1996.

[4] R. Liu, D. Cao, C. Lu, Modern Prestressed Concrete Structures Durability, Beijing: science press, 2013

[5] Y. Guo, Reinforced Concrete after Electrochemical Chlorine and Chlorine Removal Performance Study, Beijing: coal industry publishing house, 2013

[6] Z. Wang, hong-yong, W. zheng. Prevention and Treatment of Chlorine Ion in Concrete, J. Corr. Protect., vol. 23, no. 10, pp. 460-462, 2002

[7] O. Poupard, A. Ait-Mokhtar, P. Dumargue, "Corrosion by chlorides in reinforced concrete: determination of chloride concentration threshold by impedance spectroscopy", Cement Concrete Res., vol. 34, pp. 991-1000, 2004

[8] W. Z. Ouyang, X. Cao, N. Wang, "A Mathematical model for electrochemical chloride removal from marine cast iron artifacts", Acta Metall. Sin. (Engl. Lett), vol. 22, no. 2, pp. 82-85, 2009.

[9] N. Gowripalan, V. Sirivivatnanon, C. Lim, "Chloride diffiisivity of concrete cracked in flexure", Cement Concrete Res., vol. 30, no. 5, pp. 725-730, 2000 
[10] J. Li, P. Dong, "The analysis of the corrosion rate of reinforcement in concrete structures", Indust. Construct., vol. 1998, no. 1, pp. $12-15,1998$

[11] P. J. Sanchez, A. E. Huespe, J. Oliver, S. Toro, "Mesoscopic model to simulate the mechanical behavior of reinforced concrete members affected by corrosion", Int. J. Solids Struct., vol. 47, no. 5, pp.540-550, 2010
[12] K. Maekawa, R. Chaube, T. Kishi, Modelling of concrete performance: Hydration, Microstructure Formation, and Mass Transport, Taylor \& Francis, 1999

[13] L. Chemin, D. V. Val, "Prediction of corrosion-induced cover cracking in reinforced concrete structures", Construct. Build. Mat., vol. 25, no. 4, pp.1854-1869, 2011.

[14] S. J. Jaffer, C. M. Hansson, "Chloride-induced corrosion products of steel in cracked- concrete subjected to different loading conditions", Cement Concrete Res., vol. 39, no. 2, pp. 116-125, 2009

Received: September 17, 2014

Revised: December 17, 2014

Accepted: December 23, 2014

(C) Faming et al.; Licensee Bentham Open.

This is an open access article licensed under the terms of the Creative Commons Attribution Non-Commercial License (http://creativecommons.org/licenses/ by-nc/3.0/) which permits unrestricted, non-commercial use, distribution and reproduction in any medium, provided the work is properly cited. 